\title{
Examining the Relationship Between Parental Involvement and Student Motivation
}

\author{
Alyssa R. Gonzalez-DeHass, ${ }^{1,4}$ Patricia P. Willems, ${ }^{2}$ \\ and Marie F. Doan Holbein ${ }^{3}$
}

\begin{abstract}
Parent involvement has a sound research base attesting to the many potential benefits it can offer in education. However, student motivation as an academic outcome of parental involvement has only recently been investigated. The purpose of this article is to show how parent involvement is related to students' motivation. Studies of students from the elementary school to high school show a beneficial relationship between parental involvement and the following motivational constructs: school engagement, intrinsic/extrinsic motivation, perceived competence, perceived control, self-regulation, mastery goal orientation, and motivation to read. From the synthesis of the parent involvement and motivation literature, we offer potential explanations for their relationship. Directions for areas of continued research are also presented.
\end{abstract}

KEY WORDS: parent involvement; motivation; engagement.

The reauthorization of the Elementary and Secondary Education Act (ESEA), more familiar to educators as the No Child Left Behind Act (2001; NCLB), is clear. States who want to receive federal funding must comply with a specific mandate to investigate appropriate practices for involving parents in the education of their children. President George Bush describes this act as "the cornerstone of [his] Administration" (NCLB Executive Summary). States and educational agencies are rapidly

\footnotetext{
${ }^{1}$ Department of Teacher Education, Florida Atlantic University, Jupiter, Florida.

${ }^{2}$ Department of Teacher Education, Florida Atlantic University, Davie, Florida.

${ }^{3}$ Department of Curriculum \& Instruction, State University of West Georgia, Carrollton.

${ }^{4}$ Correspondence should be addressed to Alyssa R. Gonzalez-DeHass, Florida Atlantic University, 5353 Parkside Drive, Jupiter, Florida 33458; e-mail: agonzale@fau.edu.
} 
mobilizing to comply with this and other mandates contained within this lengthy piece of federal legislation that has transformed the landscape of public education for a long time. Established practices for involving parents must "be based on the most current research that meets the highest professional and technical standards, on effective parental involvement that fosters achievement to high standards for all children (ESEA, NCLB, Section 1111.d)."

The focus on scientifically based evidence is prominent in this legislation and impacts school reform at many levels. The review of research in this article on the effects of parent involvement is important to those educational agencies and other constituencies striving to meet the NCLB requirements in order to acquire funding and implement measures to improve student achievement.

Researchers have concluded that parent involvement generally benefits children's and adolescents' learning and academic success (Hoover-Dempsey and Sandler, 1997, p. 3). Studies of programs in early childhood, elementary, middle, and high schools indicate that efforts to improve student outcomes are more effective when the family is actively involved (Henderson and Berla, 1994). Greenwood and Hickman (1991) have cited numerous studies focusing on elementary grades that found relationships between parent involvement and student variables such as academic achievement, sense of well-being, attendance, student attitude, homework readiness, grades, and educational aspirations. Parental involvement is also positively related to high school students' academic achievement (Paulson, 1994; Steinberg et al., 1992; Trusty, 1996), time spent on homework (Keith et al., 1986; Trusty, 1996), favorable attitudes toward school (Trusty, 1996), and reduced levels of high school dropout (Rumberger et al., 1990). Variables such as time spent on homework, school retention, and educational aspirations are all indicative of how much students value education and how motivated they are to succeed academically.

However, student motivation as an academic outcome of parental involvement has only recently been explored. The purpose of this article is to present some of the specific types of parent involvement related to students' motivation. Conclusions drawn from the articles reviewed indicate parental involvement is related to the following motivational constructs: school engagement, intrinsic/extrinsic motivation, autonomy, self-regulation, mastery goal orientation, and motivation to read. Each of these constructs is addressed in a separate section. The final section discusses why relationships might exist between parent involvement and student motivation, and it concludes with suggestions for continued research. 


\section{HOW THE REVIEW OF LITERATURE WAS CONDUCTED}

We searched the Educational Resources Information Center (ERIC) and PsycINFO online databases. A search for all articles published since 1967 using the keywords of parent involvement and motivation yielded hundreds of results. Once overlapping articles from the two databases were removed, the abstracts were reviewed to narrow the pool to only studies that were reported in English, investigated parent involvement with academic student motivation as an outcome variable, and focused on students in grades K-12 attending public schools in the United States. We chose to focus on parent involvement in children's education, not on parent involvement in children's lives broadly. Many articles did not investigate student motivation as an outcome variable. Instead they investigated motivation as a predictor variable (along with parent involvement) for students' academic achievement. In some cases, the motivational variable was a contrived measure of a child's motivation towards a non-academic, problemsolving task. Finally, some studies were rejected because they failed to clearly define how they measured either the parent involvement or motivational construct during data collection. This selection process resulted in thirteen studies being included in the final review. Table I provides for each study included the type of publication, population served, description of the nature of parent involvement examined, and main findings. Effect sizes could not be computed for all studies because effect sizes account for the size of the difference between two means (Franenkel and Wallen, 2003), and the studies in this review did not all use mean comparisons between groups.

The selected articles explored different areas of motivation. Two studies investigated students' academic school engagement measured by either the amount of acting-out behaviors, the quality of their work habits, task orientation, tolerance, focus, or coping with failure (Izzo et al., 1999; Steinberg et al., 1992). Four studies used scales of intrinsic/extrinsic motivation as measures for academic motivation (Ginsburg and Bronstein, 1993; Marchant et al., 2001; Ames et al., 1993, 1995). Four studies examined student autonomy by looking at locus of control, control understanding, perceived competence, perceived autonomy, self-regulation, or affective coping and engagement (Grolnick and Slowiaczek, 1994; Grolnick et al., 1991; Trusty and Lampe, 1997; Stiller and Ryan, 1992). One study examined motivation as mastery and performance goal orientations (Gonzalez et al., 2002), and two studies measured motivation to read (Adunyarittigun, 1997; Koskinen et al., 2000).

We defined the construct of parent involvement in terms of parenting behaviors directed towards children's education. A range of parent 


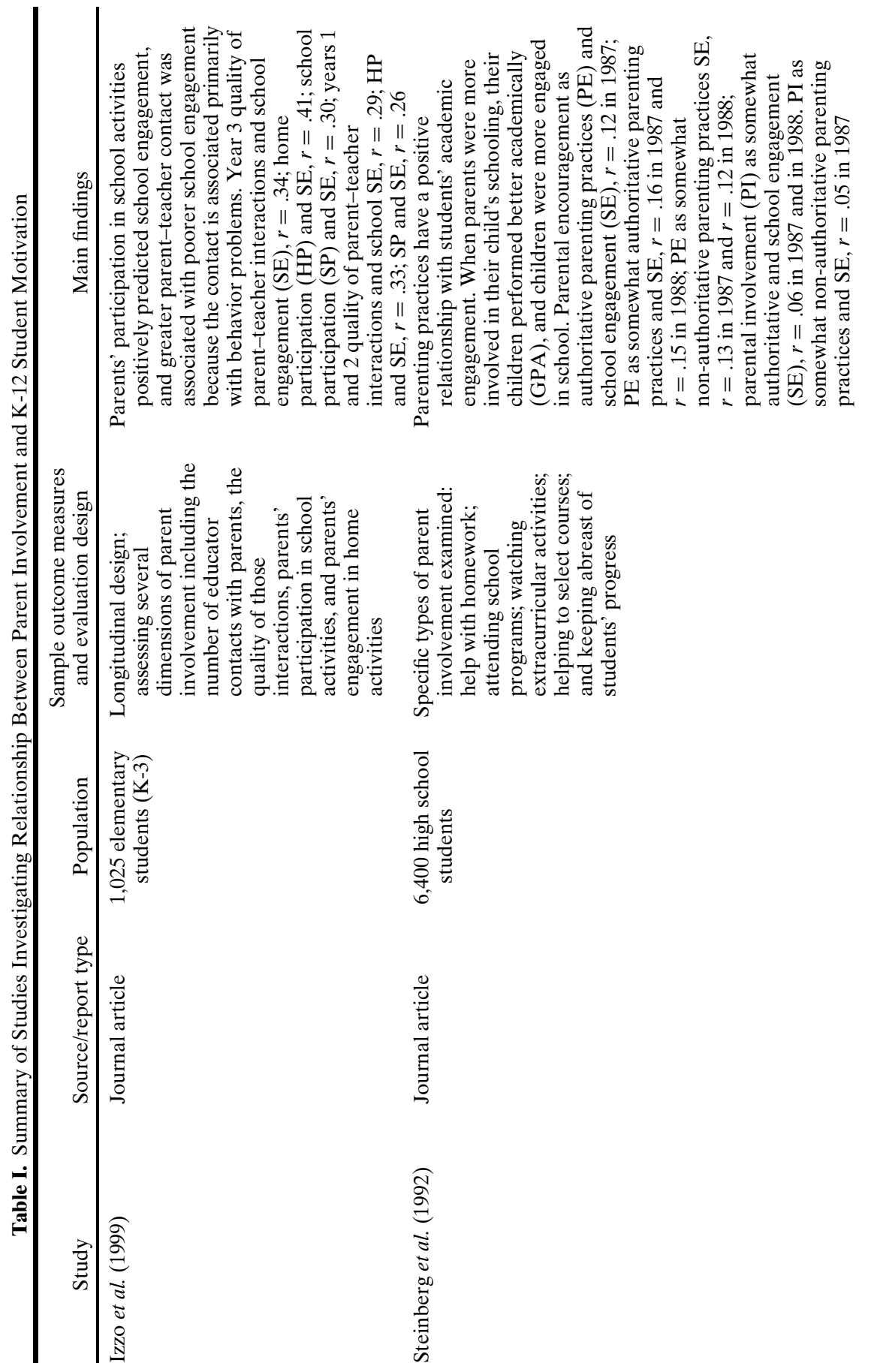




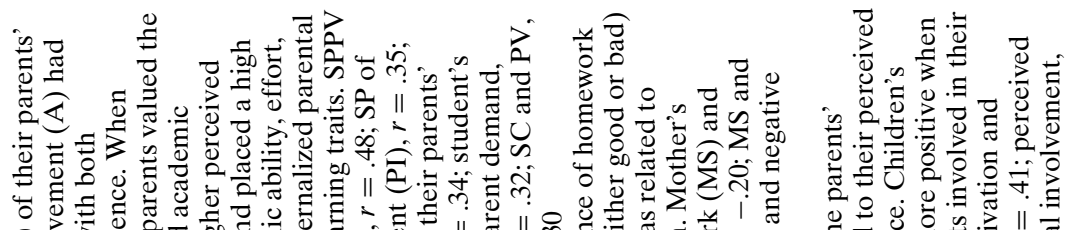
O

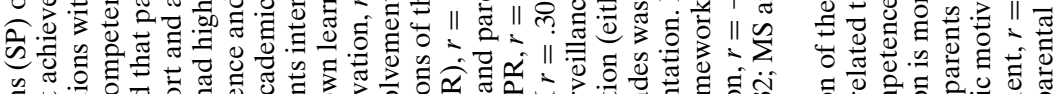

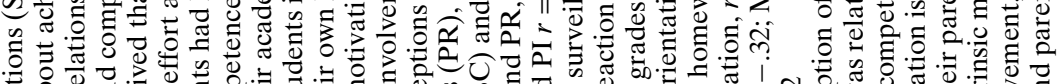

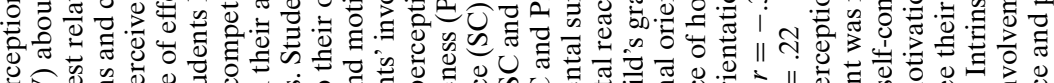

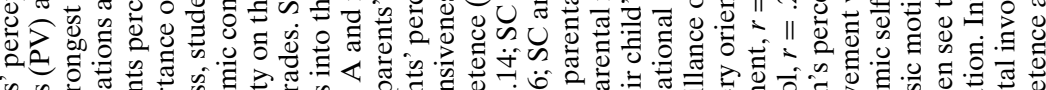

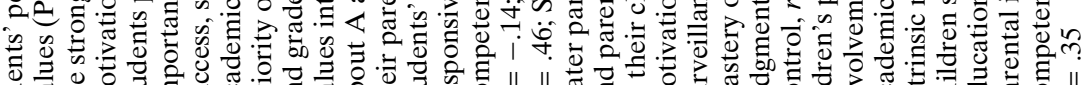

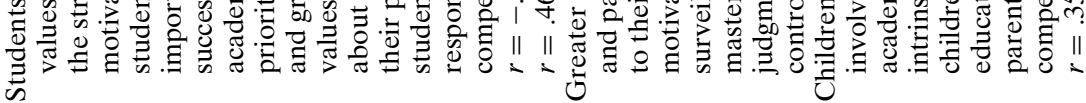
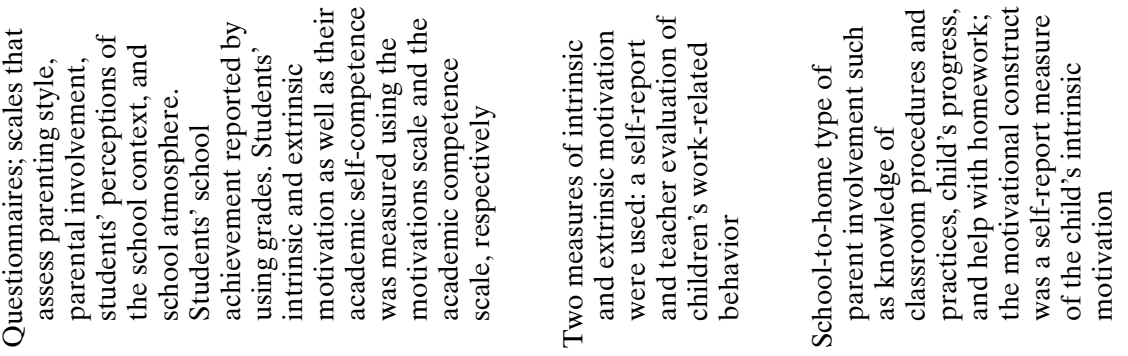

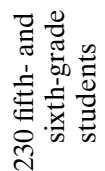
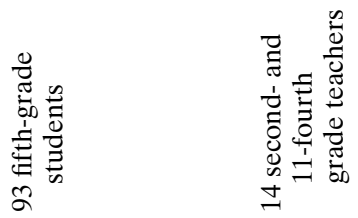

를

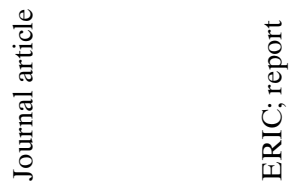

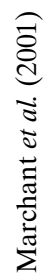

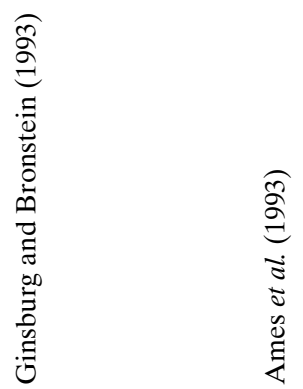




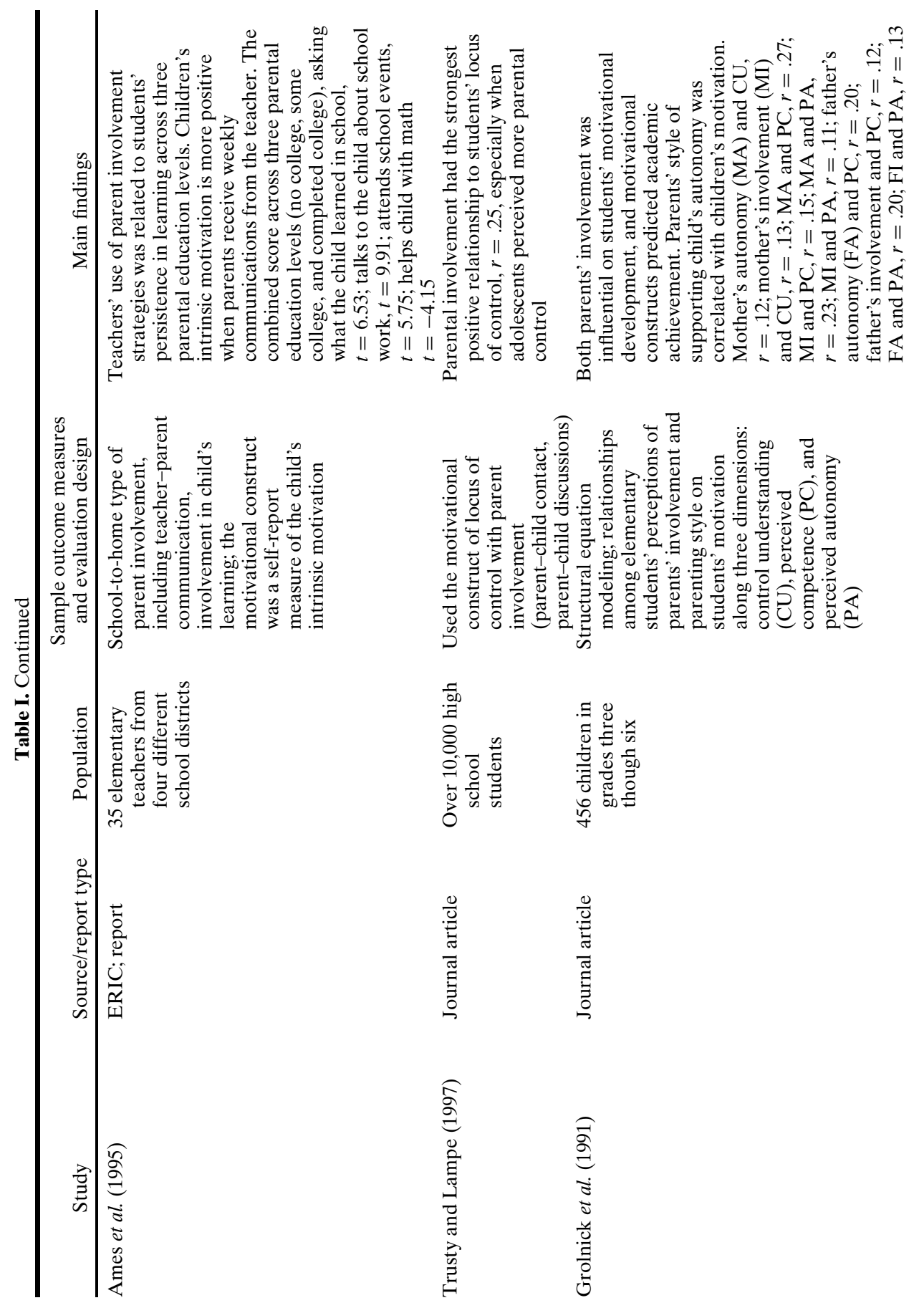




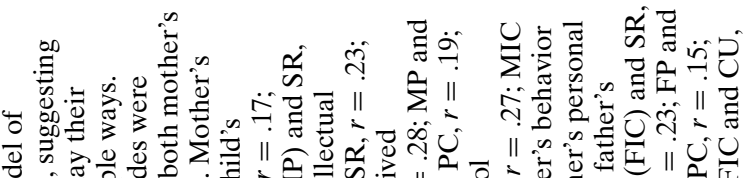

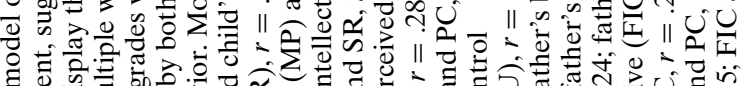

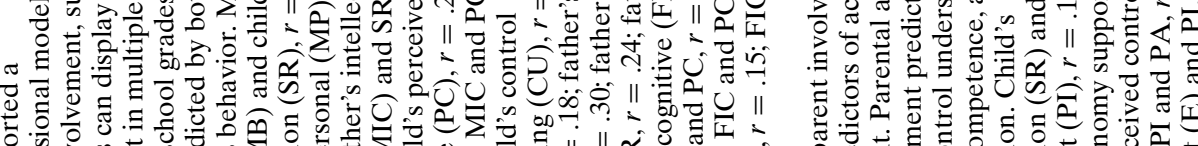

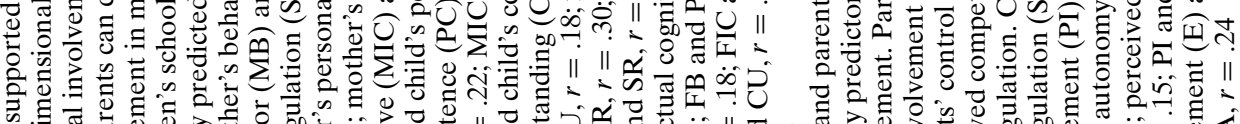

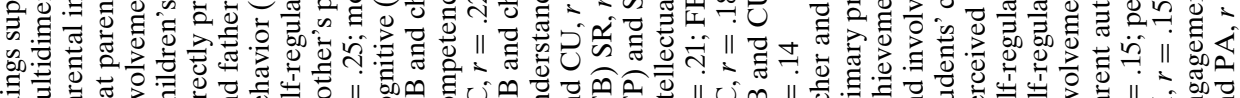

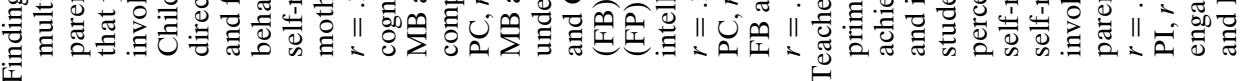
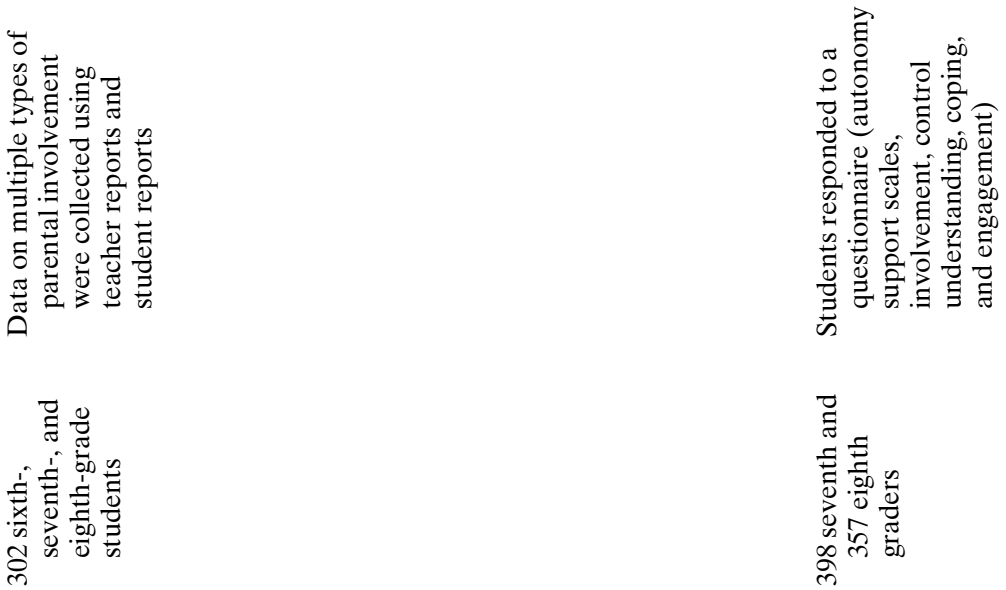

䒕

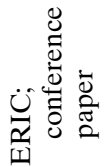

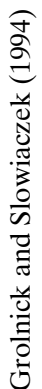

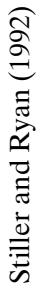




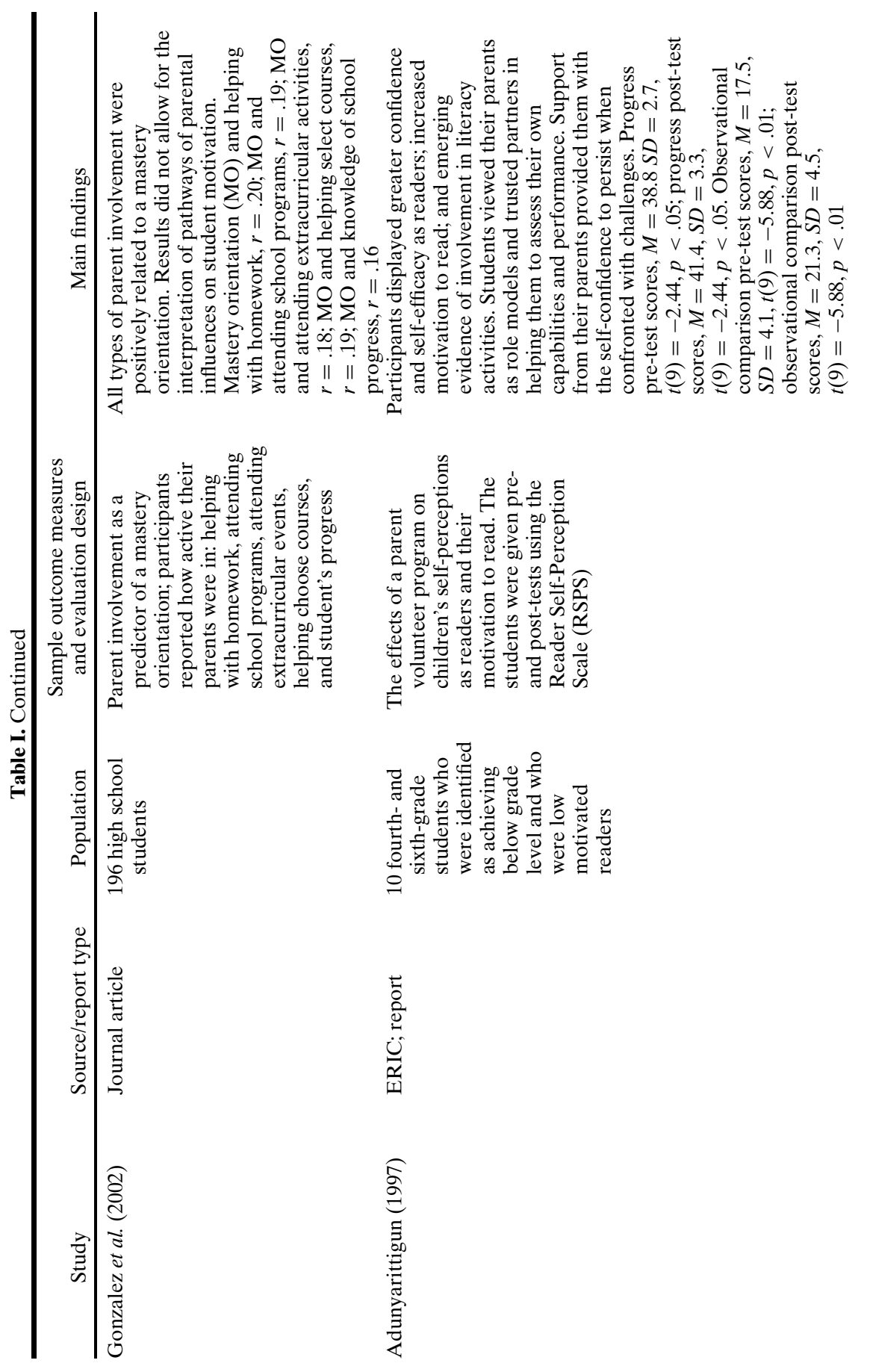



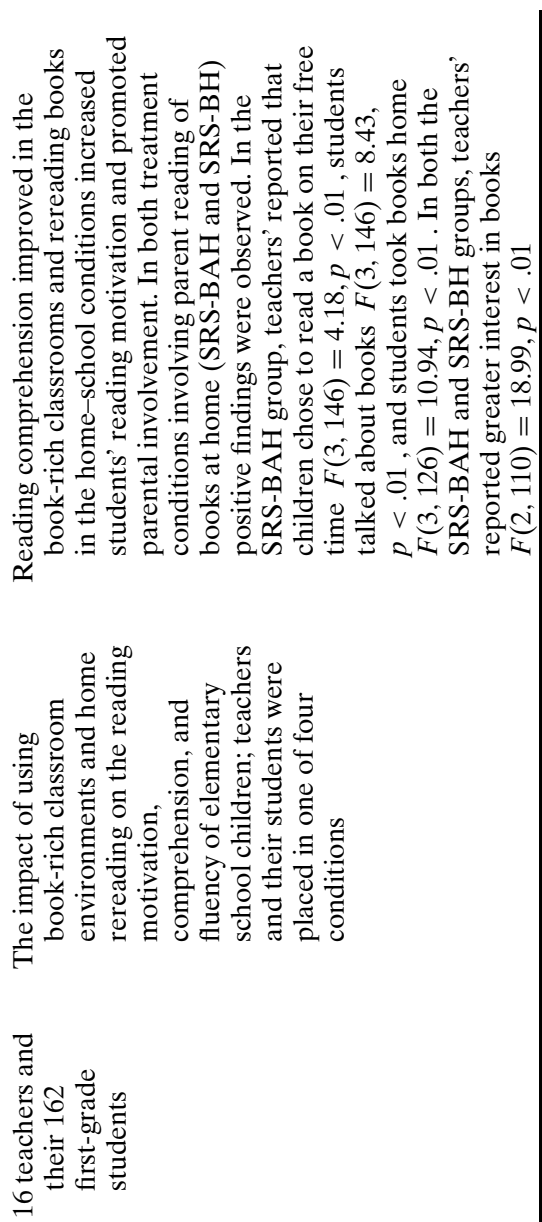

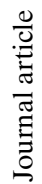

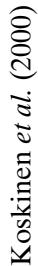


involvement activities was included in the studies reviewed in order to allow for the examination of how various parent involvement behaviors might differentially relate to student motivation. Across the studies reviewed, parental involvement was measured as participating in parent-teacher conferences and/or interactions, participating in school activities and/or functions, engaging in activities at home including but not limited to homework, engaging in students' extracurricular activities, assisting in the selection of student's courses, keeping abreast of student's academic progress, reaction to student's academic grades, imparting parental values (attitudes about the importance of effort and academic success), or the level of parental control and/or autonomy support offered in the home environment.

\section{STUDENT ENGAGEMENT}

Parenting practices can have a positive impact on students' academic engagement. Izzo et al. (1999) examined how parent involvement related to 1,025 elementary students' (kindergarten through third grade) social and academic functioning. The authors addressed a number of issues in order to fully understand the relationship between parent involvement and children's school functioning. Izzo et al. employed a three-year longitudinal design to assess several dimensions of parent involvement including the number of educator contacts with parents, the quality of those interactions, parents' participation in school activities, and parents' engagement in home activities to enhance the child's social and academic development. Of particular importance to this article is that Izzo et al. investigated how these parent involvement variables predicted students' school engagement. Engagement was measured by examining students' acting-out behaviors to gain attention, the quality of work habits, task orientation or functioning amidst distractions, tolerance for frustration, and ability to cope with failure. Results indicated that parents' participation in school activities positively predicted school engagement. Interestingly, results also showed that greater parent-teacher contact was associated with poorer school engagement. To explain the latter finding, researchers noted that behavior problems are among the most frequent reasons for parent teacher contacts. Therefore, it is not the contact that is detrimental. The negative association exists because those contacts are primarily associated with behavior problems. Izzo et al. suggested that it is advantageous for schools to focus on fostering more constructive interactions instead of counting the number of interactions. Overall, the researchers concluded that although their results do not warrant causal relationships, they do suggest that parent involvement may precede better school performance. 
In a study of 6,400 high school students from diverse socioeconomic and ethnic backgrounds, Steinberg et al. (1992) demonstrated that parenting practices also have a positive relationship with high school students' academic engagement. The specific types of parent involvement examined were helping with the students' homework, attending school programs, watching the student in sports or other extracurricular activities, helping the student to select courses, and keeping abreast of the student's progress in school. When parents were more involved in their child's schooling, their children had higher grade-point averages and were more engaged in school. Specifically, when parents were involved, students reported more effort, concentration, and attention across four main subject areas: maths, English, social studies, and science. However, these researchers concluded that parental involvement is even more likely to benefit students' school success when it occurs within an authoritative parenting style typified by parental acceptance and warmth and by behavioral supervision that allows for some degree of democracy and autonomy on the part of the child.

\section{INTRINSIC AND EXTRINSIC MOTIVATION}

The study by Marchant et al. (2001) explored the relationship of both family (parenting style and parent involvement) and school contexts on students' motivation. Researchers examined how students' perceptions of their motivations and academic self-competence mediate between these environmental contexts and academic achievement. Two hundred thirty fifth- and sixth-grade students responded to questionnaires using four scales that assessed parenting style and parental involvement. Parenting style was measured using two dimensions: demandingness (authority) and responsiveness (warmth). Parental involvement was also defined using two dimensions: parental values and parental involvement in school functions. The parental values scale included seven items that measured students' perceptions of parents' values and attitudes about the importance of effort and academic success. The parental involvement in school functions scale consisted of five items concerning students' perceptions of parental involvement in school activities. The teacher control scale and the teacher responsiveness scale were administered to measure teaching style. School atmosphere was measured using the school responsiveness scale. Students also responded to three measures designed to measure achievement outcomes. Students' school achievement was represented by their grades from the most recent grading period. Students' intrinsic and extrinsic motivation as well as their academic self-competence were measured using the motivations scale and the academic competence scale, respectively. The 
motivations scale consisted of five items addressing students' perceptions of importance of ability, effort, and grades. The academic competence scale was comprised of four items that assessed how academically competent students perceived themselves to be.

The findings from the Marchant et al. (2001) study confirm the important role that relationships among parents, teachers, and peers play on early adolescents' school achievement. In particular, students' perceptions of their parents' values about achievement had the strongest relationship with both motivations and competence. When students perceived that parents valued the importance of effort and academic success, students had higher perceived academic competence and placed a high priority on their academic ability, effort, and grades. Parental values were correlated with both parental responsiveness and involvement in school. It is noteworthy that students internalized parental values into their own learning traits. Results from this study also raise the possibility that parent involvement in the home verses participation at school may differentially relate to student motivation. This possibility would extend the range of parent involvement practices schools should seek to promote.

Other researchers have also investigated whether all types of parent involvement necessarily have a beneficial impact on student motivation. Ginsburg and Bronstein (1993) investigated parental involvement (surveillance of homework and reaction to students' academic grades) in relation to children's motivational orientation. Two measures of intrinsic/extrinsic motivation were used: a self-report and teacher evaluation of children's work-related behavior. Results from a sample of 93 fifth-grade students showed that parental surveillance of homework was related to an extrinsic motivational orientation. The more parents were involved in monitoring, enforcing, or helping with homework, the more students reported being extrinsically motivated and dependent on external sources for academic guidance and evaluation. Teachers rated these students as showing less initiation, autonomy, persistence, and satisfaction in doing their schoolwork. In this study, however, the surveillance was considered as over-controlling, and it may be necessary to examine ways that parents might be involved with schoolwork without being viewed as over-controlling. Results also indicated that when parents reacted to their child's grades (either high or low) with extrinsic rewards, that reaction was related to an extrinsic motivational orientation. Once again, teachers were more likely to rate these children as being less motivated, exhibiting less pleasure, and demonstrating less persistence in doing their schoolwork. However, when parents reacted to their grades by providing encouragement and praise, students were more likely to report an intrinsic motivational orientation characterized by a preference for challenging tasks, curiosity, and interest in learning. These findings 
support the notion that parent variables play a role in the development of children's intrinsic motivation. Findings also highlight the importance of examining separate types of involvement because not all types facilitate intrinsic motivation.

Focusing on the school-to-home communication type of parent involvement, Ames and her colleagues examined relationships, as part of a larger longitudinal project, between parent involvement and children's motivation (Ames et al., 1993, 1995). Elementary teachers from mid-western school districts participated in the study. Researchers specifically focused on the school-to-home type of parent involvement: (a) providing parents with information about classroom learning activities; (b) providing parents with information about the strengths and accomplishments of their own child; and (c) providing parents with information about how to help their child learn at home. The motivational construct was a self-report measure of the child's intrinsic interest in learning at school and included items such as "I like learning new things," "I like doing my class work," and "I work hard to learn new things." They found that children's intrinsic motivation is more positive when parents receive weekly communications from the teacher (1995) and when children see their parents involved in their education (1993). Researchers also established a relationship between parent involvement and other motivation-related outcomes. Teachers' use of parent involvement strategies was related to students' persistence in learning (1995), and children's perceptions of the parents' involvement was related to their perceived academic self-competence (1993).

Ames et al. $(1993,1995)$ suggested that parental beliefs might mediate the effect of teachers' parent involvement strategies on parent involvement efforts. Perhaps receiving such communications from the teacher enhances parents' feelings of comfort with the school, perceptions of their child as a learner, knowledge about programs and learning at the school, and belief that they can influence their child's learning. Consequently, when parents show an interest and enthusiasm for what their children are learning, they provide a support system at home that buttresses the child's academic learning and reinforces the value of schooling. By providing such emotional support, parents establish a foundation for socializing children's motivation to learn.

\section{PERSONAL CAUSATION AND SELF-REGULATION}

The preceding discussion on intrinsic and extrinsic motivation can be extended by considering the literature on locus of control. Locus of control refers to how students attribute the causes of events. They either assign 
causality internally (to factors within themselves like effort and ability) or externally (to factors outside themselves like luck or teacher favoritism). Each has a different effect on students' academic behavior. For instance, students with an internal locus are more likely to experience pride and satisfaction for their successes, and they are more likely to accept responsibility and try harder in the face of failure when they attribute those failures to lack of effort (Ormrod, 2000). Trusty and Lampe (1997) cited research showing that adolescents who are more internal in their locus of control achieve higher academically, are less alienated from school, and are more advanced in career decision-making. Using a sample of over 10,000 high school students, these researchers further demonstrated that "from highschool seniors' perspectives, parental control with parental involvement was related to internal locus of control, whereas control without involvement was related to external locus of control" (p. 375). The study examined how often parents spent time doing things with their adolescent or how often parents discussed school, job, current events, or troubling issues with their adolescent. Parental involvement had the strongest positive relationship with students' locus of control, especially when adolescents perceived more parental control. Such findings support the contemporary belief that parental support is beneficial because it offers a sense of security and comfort in a rather unpredictable society to an adolescent who is striving for self-development and a sense of identity. Two areas for continued investigation that arise from this study are the separate examination of parenting styles and parent motivation on student motivation, and research that compares parent involvement in the school verses at home.

The relationship between parent involvement and personal causation has also been examined with younger students. Grolnick et al. (1991) examined relationships among elementary students' perceptions of their parents' involvement and parenting style on students' motivation along three dimensions: control understanding (degree that children indicate they understand who or what is responsible for their school outcomes); perceived competence (extent children feel sufficiently competent to execute specific actions); and perceived autonomy (degree that initiation and regulation of action emanates from one's core sense of self). Participants were 456 children in grades three though six from a largely white and socio-economically heterogeneous school. Although students reported more parental involvement on the part of mothers, both parents' involvement was influential on students' motivational development. Paternal involvement positively predicted all three motivational constructs, whereas maternal involvement predicted control understanding. Therefore, when parents were involved, these students were more likely to know what or who controls school outcomes, feel better about their abilities, and be more autonomous. In turn, these 
motivational variables predicted children's academic achievement. In addition, both parents' style of supporting the child's autonomy was correlated with children's motivation. Although the specific nature of parent involvement examined in this study could be further clarified, the separation of parenting style and parent involvement allows for the examination of the differential impact of each parenting variable on a student's motivation. Furthermore, the use of structural equation modeling is an important step for examining the pathways of influence between parenting variables and student motivation. Given the practical limits of conducting experimental studies on parent influence, structural equation modeling provides an alternative analysis allowing for the examination of causal models and theories.

The examination into students' personal causation is extended by including the dimension of students' self-regulation. Stiller and Ryan (1992) examined the relationship between students' perceptions of parent and teacher involvement/autonomy support and student motivation. The participants were 398 seventh graders and 357 eighth graders who completed a survey during two consecutive health classes. Students were given a questionnaire with the following scales: autonomy support, involvement, control understanding, coping, and engagement. The autonomy support scales were created for this study and intended to measure students' perceptions of teacher and parent autonomy support. Parent and teacher involvement was measured using scales that were taken from the Rochester Assessment Package for Schools (RAPS). This measure was intended to assess the degree that students believe that their parents and teachers are available as resources. Control understanding indices were also taken from RAPS, and the items assessed the degree that students believe that their schoolbased outcomes are due to effort, ability, powerful others, luck, or unknown causes. The coping items also were taken from the RAPS instrument, and they assessed students' styles of affective coping with academic failure. Items forming the engagement scale were taken from RAPS as well, and they measured students' positive affect towards school. The students were also given the Self-regulation Questionnaire (Academic) (SRQ-A) that assessed students' perceptions of their reasons for performing academic behaviors. The SRQ-A contains four subscales: (a) external: indicates reliance on overtly external contingencies, (b) introjected: indicates regulation by internal pressures and contingencies, (c) identified: indicates an adoption of regulation as being personally valued, and (d) integrated: indicates a synthesis of regulation with the self such that conflict and coercion are absent.

Stiller and Ryan's (1992) findings indicated that teacher and parent involvement were primary predictors of academic achievement. Parental autonomy support was evident in a home environment that nurtures the individual's self-determination or the experience of an internal locus of 
causality. Parental autonomy and involvement predicted students' control understanding, perceived competence, and self-regulation. Teacher influences were more predictive of academic outcomes than parent influences. Authors attributed this finding to the fact that teachers are the adults most directly involved in the academic domain. However, although teachers may most directly influence how the student experiences school, parents have an additional and important bearing on student experience.

Efforts have also been undertaken to distinguish between mother and father involvement and their relationship to students' personal causation and self-regulation. Grolnick and Slowiaczek (1994) examined pathways whereby parent involvement might affect school performance, specifically how children's' motivational resources act as mediators. The participants were 302 sixth-, seventh-, and eighth-grade students from four different schools. Data on multiple types of parental involvement were collected using teacher reports and student reports. Teachers rated parental 'behavior' involvement, for both mother and father, as characterized by parentschool interaction through such activities as parent-teacher conferences, open-school nights, and school events. The same questionnaire was then given to the students to assess their perceptions of their mothers' and fathers' parent-school interaction. The parent 'personal' involvement was evaluated by students' perceptions of their mothers' and fathers' use of positive affect (parent cares about school and has positive interactions with child around school) and the extent that students perceived parents to be involved with their academic and social lives. The parent 'intellectual/cognitive' involvement dimension measured mothers' and fathers' involvement with the child using a range of intellectual and cultural activities like reading the newspaper, discussing current events, and attending lectures or musical/artistic activities. Questionnaires were used to assess students' motivational resources (self-regulation, perceived competence, and control understanding) and school competence (student grades and teacher ratings of competence).

The two goals in Grolnick and Slowiaczek's (1994) study were to examine a multidimensional conceptualization of parent involvement in childrens' schooling and to evaluate a model whereby children's motivational resources are mediators between parent involvement and children's school performance. First, the results supported a multidimensional model of parental involvement, thus suggesting that parents can display their involvement in multiple ways. Second, the results suggested indirect associations between parent involvement and school performance through the motivational resources. Yet, these associations were only supported for some types of motivational resources and some types of parental involvement. 
The study (Grolnick and Slowiaczek, 1994) found that children's school grades were directly predicted by both mothers' and fathers' behavior. Mothers' behavior was directly associated with two motivational constructs: perceived competence and control understanding of their children. Children's perceived competence was also predicted by fathers' behavior and by both mothers' and fathers' intellectual/cognitive factor. Fathers' behavior, unlike mothers', also predicted their children's self-regulation. Finally, only mothers' personal factor was associated with self-regulation. Given the overall findings, it is important for future research to clarify the type of parental involvement of interest and to include multiple indices when possible.

\section{MOTIVATIONAL GOAL ORIENTATION}

Students with mastery goals are interested in learning new skills and improving their understanding and competence, whereas students with performance goals are more concerned with proving their ability or avoiding negative judgments of their competence (Ames and Archer, 1988; Dweck and Leggett, 1988). Early investigations in this area led researchers (Dweck, 1986; Dweck and Leggett, 1988) to conclude that when students adopt mastery goals they seek out challenge, persist in the face of difficulty, view errors as opportunities to learn, and are more likely to be intrinsically motivated. In contrast, the adoption of performance goals leads to the avoidance of challenging tasks, less intrinsic motivation, and viewing errors as indicative of failure. Studies specific to the high school context have shown that the use of mastery goals is most consistently associated with beneficial achievement behaviors like the employment of better learning strategies, more positive attitudes, selection of challenging tasks (Ames and Archer, 1988), and work satisfaction (Duda and Nicholls, 1992). In addition, the use of mastery goals decreases the likelihood that low perceived ability becomes an academic handicap to students (Duda and Nicholls, 1992).

Gonzalez et al. (2002) investigated whether parent involvement (as perceived by students) is predictive of a mastery orientation approach to learning in a sample of 196 students enrolled in two Florida high schools. Participants were asked how active their parents were in: helping with homework, attending school programs, attending athletic or extracurricular events, choosing academic courses, and keeping informed about student's progress in school. Results showed that all types of parent involvement were positively related to a mastery orientation. Therefore, this study revealed the benefits of parent involvement across groups of diverse ethnicity and socioeconomic status. When parents were involved, it was predictive 
of students adopting an approach to learning where they are more likely to seek challenging tasks, persist through academic challenges, and experience satisfaction in their schoolwork. Both the authoritative parenting style (autonomy supporting while still imposing limits) and parent involvement proved beneficial to students' goal orientation in multiple regression analyses. Although this study examined the independent contributions of parenting style and parent involvement, conclusions did not allow for the interpretation of pathways of parental influences on student motivation. In addition, the effects of different types of parent involvement were not warranted in this study given that all types were positively and highly interrelated, and all were positively related to a mastery orientation. However, given a more diverse range of parent involvement activities, independent analyses of the involvement variables might uncover divergent relationships with student motivation.

\section{MOTIVATION TO READ}

Research has uncovered relationships between parent involvement and students' motivation in particular academic activities. A study by Adunyarittigun (1997) investigated the effects of a parent volunteer program on children's self-perceptions as readers and their motivation to read. The participants were 10 fourth- and sixth-grade students who were identified as achieving below grade level and who were low motivated readers. They attended a five-week class in the Summer Reading Program (SRP) at the University of Maryland. Thirteen parents of children who were attending the SRP voluntarily participated in the program. Parent participation varied from once in five weeks to three times a week. The program consisted of reading instruction from qualified clinicians and volunteer parents who assisted the students with reading, word-identification, comprehension, and reading projects. Parent volunteers listened to and assisted students when they experienced difficulty and provided encouragement. The students were given pre- and post-tests using the Reader Self-Perception Scale (RSPS). The post-test results from the RSPS indicated: greater confidence and self-efficacy as readers, increased motivation to read, and emerging evidence of involvement in literacy activities. Students viewed their parents as role models and trusted partners in helping them assess their own capabilities and performance. Support from parents provided them with the self-confidence to persist when confronted with challenges.

Other researchers have extended this examination of parent involvement in students' reading motivation by examining the role of parent involvement in the home environment. Koskinen et al. (2000) explored the 
impact of using book-rich classroom environments and home rereading on the reading motivation, comprehension, and fluency of elementary school children. Sixteen teachers and their 162 first-grade students were placed in one of four conditions: book-rich classroom environment, book-rich classroom environment and daily rereading of books at home, book-rich classroom environment and daily rereading of books with audiotapes at home, and regular reading instruction at school. Parents of children in conditions with a home rereading component were told about the school-home books program and were encouraged to help their children and listen to them read. The results suggested that reading comprehension was improved in the book-rich classrooms and that rereading books in the home-school conditions increased students' reading motivation and promoted parental involvement. Furthermore, teachers in the book-rich classes used smallgroup shared reading that increased students' opportunities for group interaction and promoted greater text engagement. Shared reading activity offers opportunities for scaffolding whereby the learner is able to take on more challenging reading tasks while the parent or more advanced peer adjusts the level of guidance to fit the learner's current understanding. The authors reported that the interaction with others bolsters students' feelings of success and increases students' motivation to read. Consequently, parents in the home-school conditions reported that their child's overall interest, enjoyment in reading, and motivation to read had increased. In fact, parents as well as teachers in the home-school conditions reported seeing students' display more interest in discussing books, reading books not assigned, and being motivated to read at home. The majority of the students in these home-school conditions also indicated they liked reading books at home and thought that practicing with the books helped them learn to read. Overall, the results of this study add to the growing body of research on strategies for fostering motivation and achievement in reading.

\section{CONCLUSIONS AND FUTURE DIRECTIONS}

Studies presented here uncover important relationships between parent involvement and specific motivational constructs. When parents are involved, students report more effort, concentration, and attention. Students are more inherently interested in learning, and they experience higher perceived competence. Although parental monitoring of homework (perceived as over-controlling) and use of extrinsic rewards in reaction to grades are linked to extrinsic motivation, providing encouragement and praise is linked to intrinsic motivation. Students whose parents are involved are more likely to take personal responsibility for their learning. When parents 
show an interest in their child's education by getting involved, students adopt a mastery goal orientation to learning where they are more likely to seek challenging tasks, persist through academic challenges, and experience satisfaction in their schoolwork. Finally, when parents become involved with students' reading activities, students demonstrate greater selfefficacy as readers, are more motivated to read, and voluntarily participate in literacy activities.

Due to the correlational nature of the majority of studies included in this review, there are many plausible explanations behind the positive relationships between parent involvement and students' motivation. Synthesizing across the findings of the studies included in this review, a number of recurring themes become apparent that might explain the relationship. The following sections present potential explanations for these positive findings and offer final caveats as to the complex nature of the relationships involved. Where warranted, each section closes with suggestions for future research.

\section{Parental Involvement and Student Motivation: Plausible Explanations}

\section{Parental Involvement Boosts Students' Perceived Control and Competence}

There is consistent evidence suggesting a relationship between parent involvement and students' perceived control and competence (Adunyarittigun, 1997; Ames et al., 1993, 1995; Grolnick et al., 1991; Koskinen et al., 2000; Marchant et al., 2001; Stiller and Ryan, 1992; Trusty and Lampe, 1997). Grolnick and Slowiaczek (1994) propose that parents may be communicating to children strategies for effectively dealing with the school. When they see their parents set such an example, students see school outcomes as more within their control. In addition, when parents are engaged as a resource for academic activities at home, the bridge between the school and home environments becomes more apparent. Consequently, the child feels more efficacious to master academic activities at school. Parents can facilitate students' learning new material by helping them scaffold new concepts. When students view parents as models and trusted partners in learning, it helps them assess their own capabilities and performance (Adunyarittigun, 1997). Generally, students' perceptions of ability and control influence their motivation (Stipek, 1998). "No child or adult enjoys confronting tasks that engender feelings of incompetence... being confident of success is an essential ingredient for effective learning. Without this, 
students will not engage in productive learning behaviors." (Stipek, 1998, p. 92). In addition, students are more likely to enjoy and be motivated by those activities they believe they are doing because they want to do them.

\section{Parental Involvement Offers a Sense of Security and Connectedness}

Another plausible postulate is that parental support offers a sense of security and comfort in an unpredictable society as the adolescent strives for growth and self-development (Trusty and Lampe, 1997). When parents are involved, they can set limits, provide encouragement, and act as resources as children encounter the academic, social, and personal challenges each new day brings. Parent involvement communicates to children how important they are to their parents. Parents who attend parent-teacher conferences, open houses, or other school activities show how important their children are to them (Grolnick and Slowiaczek, 1994). This support is especially vital to adolescents who are particularly at risk of disengaging from school. In the context of a permissive parenting style and a lack of parent involvement, at-risk adolescents are more likely to turn to peers in excess, potentially leading to negative outcomes such as improper social attitudes and behaviors, truancy, drug use, depression, poor grades, poor attendance, school disciplinary problems, and dropout (Rumberger et al., 1990).

\section{Parental Involvement Helps Students to Internalize Educational Values}

Another possible explanation for the link between parent involvement and student motivation is that, through their involvement, parents communicate the importance of education. Students become motivated when they observe their parents take an active interest in school. When parents show an interest and enthusiasm for what their children are learning, they provide a support system at home that buttresses the child's academic learning and reinforces the value of schooling (Ames et al., 1995). By providing such emotional support, parents establish a foundation for socializing children's motivation to learn. Being involved sends the message that parents are committed to the importance of a good education, and their attempts to stay involved are a testament to this commitment (Lamborn et al., 1992). However, it may be that the values conveyed, more than the behavioral characteristics of parent involvement, are beneficial (Marchant et al., 2001). When students perceived that parents valued the importance of effort and academic success, students were more motivated and had higher perceived academic competence (Marchant et al., 2001). Future 
research using multiple indices of parent involvement should continue to tease apart the relationship between parent involvement and students' motivation.

\section{Student Motivation Encourages Parental Involvement}

Because most of the research examining parental involvement and student motivation is correlational and precludes causal explanations, an alternative explanation for the relationship between parental involvement and student motivation is also possible. Parents may become more involved when they believe their child is motivated, or the motivated child may seek out more involvement from the parent (Ames et al., 1993). As Grolnick and Slowiaczek (1994) suggest, relationships between parenting and student outcomes may reflect child-to-parent pathways. "Children who are confident in school and feel in control of school outcomes may actually push parents to become actively involved in school... It is not inconceivable that more motivated children may suggest activities such as going to the library to their parents" (p. 249). Results may even be the outcome of circular pathways where students' motivation fuels parent involvement that further fuels students' motivation. Given the practical limits on conducting experimental studies on parent influence, statistical analyses such as path analysis and structural equation modeling might illuminate causal models and the directions of influence.

\section{Multidimensional Conceptualizations of Parental Involvement}

Studies reviewed in this article indicate that parent involvement, both in the home or school context, is associated with positive outcomes for the student's motivation. Studies measured a range of parent involvement behaviors including parents' attending school programs, remaining abreast of students' progress in school, providing assistance and encouragement, communicating the value of schooling, and engaging their child academically and intellectually in the home. However, it is also important to closely examine the effects of different types of parent involvement on academic motivation. For instance, if students perceive parental assistance in the home as over-controlling or if parents use extrinsic rewards, students may become dependent on external sources to guide their behavior (Ginsburg and Bronstein, 1993). Other results indicate that simply increasing the number of parent-teacher contacts may not be the most advantageous for students' motivation (particularly when those interactions focus solely on children's 
instances of misbehavior at school); it is the quality of these interactions that must be enhanced (Izzo et al., 1999).

A theme emerged from the literature that emphasized the benefits of parents' involvement in the home context (Koskinen et al., 2000; Marchant et al., 2001). In particular, students' perceptions of their parents' values about learning and achievement have the strongest relationships with both motivations and competence (Marchant et al., 2001). Given this finding, the most overt display of involvement at open houses and volunteering opportunities may not always be the parent involvement behavior educators should consider foremost. The practical implication for educators is that there are a range of opportunities for involvement that are beneficial, and these opportunities do not always necessarily involve the parent coming to school. This would be a refreshing realization for most teachers who seek to encourage parent involvement and are continually confronted with the reality of scheduling conflicts and transportation difficulties that arise for many parents. However, a better understanding as to the merits of different forms of parent involvement requires further investigation with diverse student populations.

Investigation should also tease apart the differential influence of parenting style and involvement on student motivation. Benefits of parental involvement may be more beneficial to students' school success when it occurs within an authoritative parenting style which is typified by parental acceptance and warmth and by behavioral supervision that allows for some degree of democracy and autonomy on the part of the child (Steinberg et al., 1992). Will parent involvement be perceived as positive when children see their parents within an authoritarian parenting style? Would permissive parents tend to be uninvolved in their child's education? Future parent involvement research that distinguishes between neglectful and indulgent parenting would help to clarify this issue. It may be that one parenting variable has a more substantial influence on student motivation. Marchant et al. (2001) concluded that parent involvement that communicates achievement as a worthwhile enterprise, rather than general parenting style, was more strongly related to student motivation. Although educators can only realistically influence the variable of parent involvement, researchers should continue to separate these two parenting variables in order to determine their unique influence on students' motivation.

As research continues to untangle the complexities of how parent involvement positively influences student motivation, parent involvement will continue to be of interest to both academics and practitioners. Continued investigation into the relationship between parent involvement and 
motivational constructs will strengthen the support for an already sound educational strategy.

\section{REFERENCES}

Adunyarittigun, D. (1997). Effects of the Parent Volunteer Program Upon Students' SelfPerception as a Reader, ERIC Document Reproduction Service No. ED404617, University of Maryland, College Park, MD.

Ames, C., and Archer, J. (1988). Achievement goals in the classroom: Students' learning strategies and motivation processes. J. Educ. Psychol. 80(3): 260-267.

Ames, C., de Stefano, L., Watkins, T., and Sheldon, S. (1995). Teachers' School-to-Home Communications and Parent Involvement: The Role of Parent Perceptions and Beliefs (Report No. 28). East Lansing, MI: ERIC Document Service No. ED383451, Center on Families, Communities, Schools, and Children's Learning, Michigan State University.

Ames, C., Khoju, M., and Watkins, T. (1993). Parent Involvement: The Relationship Between School-to-Home Communication and Parents' Perceptions and Beliefs (Report No. 15). Urbana, IL: ERIC Document Service No. ED362271, Center on Families, Communities, Schools, and Children's Learning, Illinois University.

Duda, J. L., and Nicholls, J. G. (1992). Dimensions of achievement motivation in schoolwork and sport. J. Educ. Psychol. 84(3): 290-299.

Dweck, C. S. (1986). Motivational processes affecting learning. Am. Psychol. 41(10): 10401048.

Dweck, C. S., and Leggett, E. L. (1988). A social-cognitive approach to motivation and personality. Psychol. Rev. 95(2): 256-273.

Franenkel, J. R., and Wallen, N. E. (2003). How to Design and Evaluate Research in Education, McGraw-Hill, New York.

Ginsburg, G. S., and Bronstein, P. (1993). Family factors related to children's intrinsic/extrinsic motivational orientation and academic performance. Child Dev. 64: 1461-1474.

Gonzalez, A., Doan Holbein, M., and Quilter, S. (2002). High school students' goal orientations and their relationship to perceived parenting styles. Contemp. Educ. Psychol. 27: $450-470$.

Greenwood, G. E., and Hickman, C. W. (1991). Research and practice in parent involvement: Implications for teacher education. Element. School J. 91(3): 279-288.

Grolnick, W. S., Ryan, R. M., and Deci, E. L. (1991). Inner resources for school achievement: Motivational mediators of children's perceptions of their parents. J. Educ. Psychol. 83(4): 508-517.

Grolnick, W. S., and Slowiaczek, M. L. (1994). Parents' involvement in children's schooling: A multidimensional conceptualization and motivational model. Child Dev. 65: 237-252.

Henderson, A. T., and Berla, N. (1994). A New Generation of Evidence: The Family is Critical to Student Achievement, National Committee for Citizens in Education, Columbia, MD.

Hoover-Dempsey, K. V., and Sandler, H. M. (1997). Why do parents become involved in their children's education? Rev. Educ. Res. 67(1): 3-42.

Izzo, C. V., Weissberg, R. P., Kasprow, W. J., and Fendrich, M. (1999). A longitudinal assessment of teacher perceptions of parent involvement in children's education and school performance. Am. J. Community Psychol. 27(6): 817-839.

Keith, T. Z., Reimers, T. M., Fehrmann, P. G., Pottebaum, S. M., and Aubey, L. W. (1986). Parental involvement, homework, and TV time: Direct and indirect effects on high school achievement. J. Educ. Psychol. 78(5): 373-380.

Koskinen, P. S., Blum, I. H., Bisson, S. A., Phillips, S. M., Creamer, T. S., and Baker, T. K. (2000). Book access, shared reading, and audio models: The effects of supporting the literacy learning of linguistically diverse students in school and at home. J. Educ. Psychol. 92(1): 23-36.

Lamborn, S. D., Brown, B. B., Mounts, N. S., and Steinberg, L. (1992). Putting school in perspective: The influence of family, peers, extracurricular participation, and part-time work 
on academic engagement. In Newmann, F. M. (ed.), Student Engagement and Achievement in American Secondary Schools, Teachers College Press, New York, pp. 153-181.

Marchant, G. J., Paulson, S. E., and Rothlisberg, B. A. (2001). Relations of middle school students' perceptions of family and school contexts with academic achievement. Psychol. Schools 38(6): 505-519.

No Child Left Behind Act. (2001). Retrieved September 23, 2004, from U.S. Department of Education Web site: http://www.ed.gov/policy/.

Ormrod, J. E. (2000). Educational Psychology: Developing Learners (3rd ed.), Prentice-Hall, Upper Saddle River, NJ.

Paulson, S. E. (1994). Relations of parenting style and parental involvement with ninth-grade students' achievement. J. Early Adolesc. 14(2): 250-267.

Rumberger, R. W., Ghatak, R., Poulos, G., Ritter, P. L., and Dornbusch, S. M. (1990). Family influences on dropout behavior in one California high school. Sociol. Educ. 63: 283-299.

Steinberg, L., Lamborn, S. D., Dornbusch, S. M., and Darling, N. (1992). Impact of parenting practices on adolescent achievement: Authoritative parenting, school involvement, and encouragement to succeed. Child Dev. 63: 1266-1281.

Stiller, J. D., and Ryan, R. M. (1992, April). Teachers, Parents, and Student Motivation: The Effects of Involvement and Autonomy Support, Paper Presented at the Annual Meeting of the American Educational Research Association, San Francisco, CA.

Stipek, D. (1998). Motivation to Learn: From Theory to Practice, Allyn and Bacon, Needham Heights, MA.

Trusty, J. (1996). Relationship of parental involvement in teens' career development to teens' attitudes, perceptions and behavior. J. Res. Dev. Educ. 30(1): 63-69.

Trusty, J., and Lampe, R. E. (1997). Relationship of high-school seniors' perceptions of parental involvement and control to seniors' locus of control. J. Couns. Dev. 75(5): 375384. 